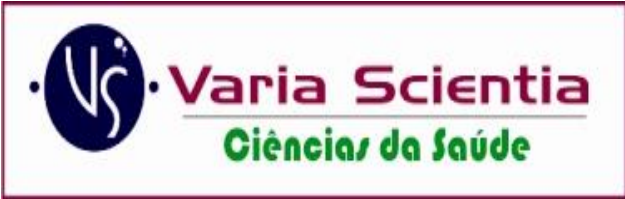

e-ISSN 2446-8118

\title{
PROBLEMÁTICAS DE SAÚDE PÚBLICA EM REGIÃO DE TRÍPLICE FRONTEIRA: UMA REVISÃO INTEGRATIVA
}

\section{PUBLIC HEALTH ISSUES IN THE TRIPLE BORDER REGION: AN INTEGRATIVE REVIEW}

\section{CUESTIONES DE SALUD PÚBLICA EN LA REGIÓN DE LA TRIPLE FRONTERA: UNA REVISIÓN INTEGRATIVA}

RESUMO: Regiões de fronteira guardam em si complexos desdobramentos provenientes de eventos e causas socioculturais, que necessitam ser ponderados quando são desenvolvidas políticas públicas de saúde, dado que além do aspecto geográfico, essas regiões caracterizam-se pelas distintas e multifacetadas analogias e inter-relações próprias. Objetivo: Analisar as problemáticas de saúde pública em região de tríplice fronteira entre Brasil, Argentina e Paraguai bem como, contrastar com o atual cenário da pandemia da Covid-19. Método: Trata-se de um estudo de revisão integrativa realizado entre outubro e dezembro de 2020 com base em periódicos nacionais e internacionais abordando assuntos relacionados ao tema. As bases consultadas foram: 1. Portal de periódicos da Capes (CAPES); 2. Literatura Latino-Americana e do Caribe em Ciências da Saúde (LILACS); 3. Scientific Electronic Library Online (SciELO). Resultados: A partir das definições, critérios e combinações de palavras-chaves definidas para o estudo foram localizadas 156 publicações. A amostra final foi composta por 10 artigos. Conclusão: Após análise na íntegra, constatou-se que, se na conjuntura antecedente à crise sanitária do Covid-19, a população em geral já se deparava com desafios de acesso à saúde, se faz imprescindível e urgente pensar em políticas de saúde por meio de atuações intergovernamentais e uma participação mais intensa dos Ministérios de Saúde dos países fronteiriços para debater e implantar medidas de migração e saúde, pois a falta de articulação política migratória e de saúde expõe estes indivíduos à precarização de suas vidas, e de condição humana.

DESCRITORES: Tríplice fronteira; Saúde pública; Políticas Públicas de Saúde; Pandemia; Covid 19.

\begin{abstract}
Border regions contain complex consequences arising from sociocultural events and causes, which need to be considered when public health policies are developed, given that, in addition to the geographic aspect, these regions are characterized by distinct and multifaceted analogies and their own interrelationships. Objective: To analyze public health problems in the triple border region between Brazil, Argentina and Paraguay, as well as contrast with the current scenario of the Covid19 pandemic. Method: This is an integrative review study carried out between October and December 2020 based on national and international journals addressing issues related to the topic. The databases

\footnotetext{
${ }^{1}$ Universidade Estadual do Oeste do Paraná - Campus Foz do Iguaçu. Brasil. Possui graduação em Enfermagem pela Faculdade União das Américas (2006), especialização em enfermagem obstétrica pelo Instituto Filadélfia (2011), especialização em gestão hospitalar e dos serviços de saúde pela Univel (2007), especialização em licenciatura do programa de formação de docentes para educação básica e pro pelo Centro Universitário Dinâmica das Cataratas (2016), especialização em Educação Profissional e Tecnologia pela Faculdade de Educação São Luís (2019) e especialização em Gestão Pública pela Faculdade de Educação São Luís (2019). Atualmente é enfermeira do Centro Materno Infantil e Professor da escola Jorge Shimmelpfeng.
} 
consulted were: 1. Capes Journal Portal (CAPES); 2. Latin American and Caribbean Health Sciences Literature (LILACS); 3. Scientific Electronic Library Online (SciELO). Results: From the definitions, criteria and combinations of keywords defined for the study, 156 publications were located. The final sample consisted of 10 articles. Conclusion: After a full analysis, it was found that, if in the context prior to the Covid-19 health crisis, the general population was already faced with challenges of access to health, it is essential and urgent to think about health policies through of intergovernmental actions and a more intense participation of the Ministries of Health of the bordering countries to debate and implement measures for migration and health, as the lack of political articulation for migration and health exposes these individuals to the precariousness of their lives, and of human condition.

DESCRIPTORS: Triple border; Public health; Public Health Policies; Pandemic; Covid-19.

RESUMEN: Las regiones fronterizas contienen consecuencias complejas derivadas de eventos y causas socioculturales, que deben ser consideradas cuando se desarrollan políticas de salud pública, dado que, además del aspecto geográfico, estas regiones se caracterizan por analogías distintas y multifacéticas y sus propias interrelaciones. Objetivo: Analizar los problemas de salud pública en la región de la triple frontera entre Brasil, Argentina y Paraguay, así como contrastar con el escenario actual de la pandemia Covid-19. Método: Se trata de un estudio de revisión integradora realizado entre octubre y diciembre de 2020 con base en revistas nacionales e internacionales que abordan temas relacionados con el tema. Las bases de datos consultadas fueron: 1. Portal de Revistas Capes (CAPES); 2. Literatura Latinoamericana y del Caribe en Ciencias de la Salud (LILACS); 3. Biblioteca Electrónica Científica en Línea (SciELO). Resultados: A partir de las definiciones, criterios y combinaciones de palabras clave definidas para el estudio, se localizaron 156 publicaciones. La muestra final estuvo formada por 10 artículos. Conclusión: Luego de un análisis completo, se encontró que, si en el contexto previo a la crisis de salud del Covid-19, la población en general ya enfrentaba desafíos de acceso a la salud, es fundamental y urgente pensar en políticas de salud a través de acciones intergubernamentales y una participación más intensa de los Ministerios de Salud de los países limítrofes para debatir e implementar medidas para la migración y la salud, ya que la falta de articulación política para la migración y la salud expone a estos individuos a la precariedad de su vida y de la realidad humana. condición.

DESCRIPTORES: Triple borde; Salud pública; Políticas de salud pública; Pandemia; Covid-19.

\section{INTRODUÇÃO}

Processos de integração regional entre países para a implementação de mercados comuns estão acentuando-se cada vez mais na conjuntura da globalização, e vagarosamente uma agenda social de integração é estabelecida seguindo a normatização da livre movimentação de pessoas, produtos, serviços e capital, bases econômicas de um mercado único. ${ }^{1}$ No Mercado Comum do Sul (MERCOSUL), demandas sociais e aspectos de cooperação no campo dos sistemas de saúde, gradualmente têm sido anexados à agenda política dos governantes da região. ${ }^{1}$

Dentre as diferentes necessidades de serviços que deve o Estado oferecer, a saúde se destaca como prioridade, em especial após a emergência sanitária representada pela Covid19. Nos debates de cuidados em saúde, emergem culturas, crenças, significações e, frente a uma intranquilidade, acresce a fragilidade e a percepção de impotência. ${ }^{2}$ Nessas situações, um sistema de saúde que esteja de portas abertas, onde quer que estejam as pessoas diminuiria a sensação de fragilidade e impotência tão presente na situação vivenciada na pandemia.

Em região de fronteira, como no caso desse estudo, o atual cenário tem apontado que, em busca por cuidados de saúde, os brasileiros que migraram para o Paraguai ou a Argentina, majoritariamente por motivos econômicos, e residem próximo à fronteira, regressam ao seu país de origem. ${ }^{2}$ Essa busca sofre influência de diversos motivos, entre eles a impressão de 
pertencimento, os impasses de obtenção de direitos de maneira equânime no país de morada, a demanda econômica, a organização do sistema de saúde, entre outros. ${ }^{3}$

O sistema de saúde brasileiro - Sistema Único de Saúde (SUS) - cobre atenção gratuita a todos os cidadãos brasileiros, tendo em vista que a saúde é um direito constitucional no Brasil. ${ }^{4}$ Nesse contexto, é preocupante o caso dos municípios de fronteira, onde diversos brasileiros residentes no exterior procuram atendimento de saúde. ${ }^{5}$

Nesses municípios, como em geral em outros no Brasil, a organização e o financiamento de serviços de saúde municipais são fundamentados na população habitante. Assim, o acolhimento aos não residentes institui um desequilíbrio entre a demanda e a oferta de serviços de saúde. ${ }^{5}$

"[...] Essa demanda adicional sobrecarrega os serviços de saúde e afeta a qualidade da atenção prestada. As principais limitações para absorver a demanda adicional são a falta de recursos humanos capacitados, a insuficiência de equipamentos para a realização de procedimentos de média e alta complexidade e a distância entre os municípios e os centros de referência". 6:214

Desse modo, a tríplice fronteira, delimitada pelas cidades de Foz do Iguaçu, no Brasil, Ciudad Del Este, no Paraguai e Puerto Iguazu, na Argentina, torna-se uma região que beneficia encontros, trocas, mistura de culturas, intercâmbio monetário e também de atenção às necessidades, dentre elas, a de saúde. ${ }^{7}$ A busca dos brasileiros não residentes, por serviços de saúde no Brasil tem acarretado obstáculos financeiros ao município de Foz do Iguaçu, que presta a assistência, mas não recebe o proporcional retorno financeiro do sistema de saúde, dado que o número de ações e serviços excede o número de habitantes da cidade. $^{8}$

A região tri nacional possui amplo fluxo de pessoas, que se movem entre os três países - tanto residentes que visitam os países vizinhos para trabalho, estudo ou lazer, como turistas de todo o mundo, fascinados pelos encantos naturais da região ou pela probabilidade de compras. ${ }^{9}$ Essa relação de povos demanda das autoridades de saúde um empenho ininterrupto, por constituírem condições favoráveis para a disseminação de doenças. $^{9}$

"[...] A preocupação com a circulação internacional de doenças não é nova no campo da saúde. Ganhou evidência nas últimas duas décadas com a aceleração da circulação mundial de pessoas, mercadorias, informação e também doenças, no bojo do processo conhecido como "globalização" e do fenômeno denominado "emergência de doenças". Tal processo impulsiona os estudos que tratam da relação limites, fronteiras e saúde". 10:31

Diante deste contexto, de porosidade e complexidade das fronteiras, é que se faz imperativo destacar o atual panorama da pandemia da Covid-19. No começo do mês de março de 2020, a Organização Mundial da Saúde (OMS) afirmou que o coronavírus (SARS-CoV-2) era responsável pela pandemia mundial da Doença do Coronavírus 2019 Covid-19.

Perante deste reconhecimento pela OMS, múltiplos países fecharam suas fronteiras, alguns de maneira parcial (mantendo a abertura para nacionais $\mathrm{e}$ migrantes residentes) outros de forma integral, mantendo-se fechada até mesmo para nacionais. ${ }^{11}$

Neste cenário, observa-se que o colapso sanitário da Covid-19 provoca uma nova realidade a ser encarada nas regiões de tríplice fronteira em específico na região entre Brasil, Argentina e Paraguai que é o foco do presente estudo. Gadelha e Costa, ${ }^{6}$ apontam que dentre as principais dificuldades observadas nas áreas de fronteira, a circulação das populações residentes em fluxos, nos dois sentidos, buscando a melhor oferta de ações e de serviços de saúde se destaca. Essa mobilidade origina diferentes dificuldades para os gestores de saúde dos municípios brasileiros e dos países vizinhos, como dificuldades diplomáticas e barreiras jurídicas e operacionais de saúde pública. ${ }^{6}$

Dessa forma, levando em consideração que regiões de fronteira guardam em si complicados desdobramentos, o objetivo do presente estudo é analisar as problemáticas de saúde pública em região de tríplice fronteira entre Brasil, Argentina e Paraguai bem como, contrastar (em que sentido seria este contraste: 
Resposta: se o contexto da pandemia agravou ou não as problemáticas enfrentadas em zonas de fronteira ) com o atual cenário da pandemia da Covid-19 por meio de um realizar levantamento bibliográfico

\section{MATERIAIS E MÉTODOS}

Trata-se de uma revisão integrativa com abordagem qualitativa de natureza exploratória, que consiste em um método de pesquisa da prática baseada em evidências, pois sintetiza as pesquisas disponíveis sobre determinado tema, fundamentando-se em conhecimento científico. ${ }^{12} \mathrm{O}$ processo de elaboração do presente estudo foi realizado entre outubro e dezembro de 2020 e apresentou as seguintes fases: (i) definição da pergunta norteadora, estratégia de busca na literatura, identificação dos estudos e coleta de dados; (ii) análise dos estudos incluídos; (iii) discussão dos resultados (iiii) apresentação da revisão integrativa. ${ }^{12}$

\section{Definição da pergunta norteadora}

Quais são as problemáticas de saúde pública que estão sendo enfrentadas na região de tríplice fronteira entre Brasil, Argentina e Paraguai e qual o seu contraste com a atual pandemia da Covid-19?

\section{Estratégia de busca na literatura}

Realizou-se um levantamento de publicações em três bases de dados: 1. Portal de periódicos da Capes (CAPES); 2. Literatura Latino-Americana e do Caribe em Ciências da Saúde (LILACS); 3. Scientific Electronic Library Online (SciELO). A pesquisa envolveu as seguintes combinações de palavras-chave: (a) tríplice fronteira "and" saúde pública; (b) tríplice fronteira "and" pandemia.

\section{Critérios de inclusão}

As publicações resultantes da busca nas bases de dados foram selecionadas a partir dos seguintes critérios de inclusão:

- Publicações disponibilizadas nas línguas portuguesa, inglesa ou espanhola;

- Disponibilidade dos textos na versão integral;

- Período de publicação entre 2015 e 2020;

- Busca por artigos científicos, excluindo-se outros tipos de trabalhos (teses, dissertações, livros e resenhas).

\section{Critérios de exclusão}

Os critérios de exclusão foram as publicações em duplicidade nas diferentes bases de dados e aquelas em que o objeto de estudo não estabelecia relação com o tema abordado.

\section{Identificação dos estudos e coleta de dados}

Inicialmente todos os estudos identificados na pesquisa foram avaliados a partir de seus títulos e/ou resumos. Posteriormente, os estudos que atenderam aos critérios de inclusão foram recuperados para leitura do texto completo e nova avaliação quanto aos critérios de inclusão. Do total de estudos selecionados, foi feita uma leitura prévia e identificados alguns eixos temáticos para análise. Após essa etapa, as informações extraídas dos estudos selecionados incluíram: título, ano de publicação, idioma, o objeto do estudo e base de dados onde foi publicado. A Figura 1 apresenta o fluxograma desenvolvido para atender o objetivo do estudo. 
Figura 1 - Fluxograma do processo metodológico de busca e análise dos estudos.
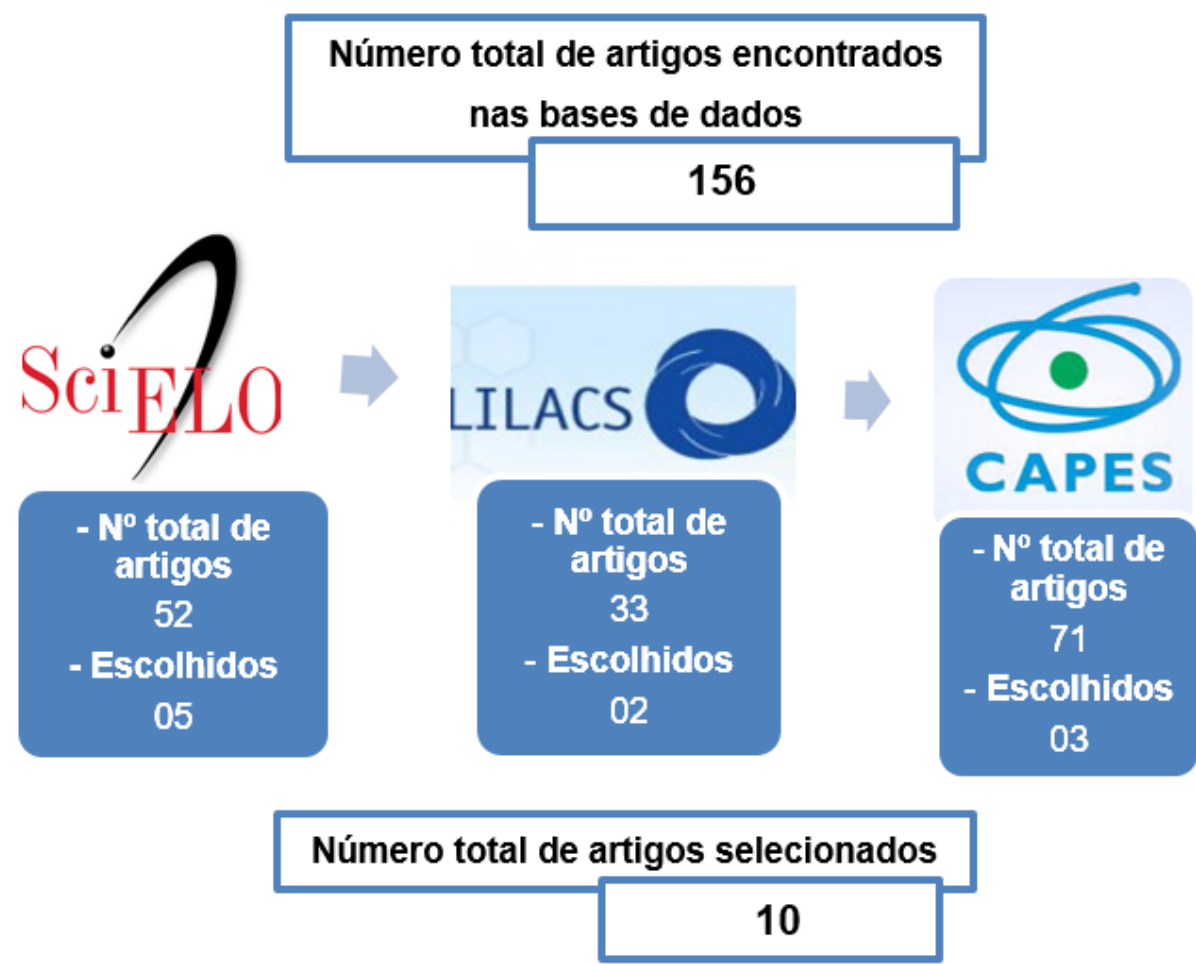

Fonte: Dados da pesquisa (2020).

\section{Discussão dos resultados}

A discussão dos resultados foi realizada de forma exploratória e comparativa, a partir da interpretação e síntese dos autores abordados, baseando-se na literatura científica do assunto e visando atender ao objetivo proposto do estudo.

\section{RESULTADOS E DISCUSSÃO}

Foram selecionados 10 artigos para análise, sendo cinco (50\%) da base de dados SciELO, três (30\%) da base de dados Capes e os demais da base Lilacs. Com relação a escrita, nove dos 10 artigos selecionados são escritos na língua portuguesa e um na língua inglesa. Quanto ao ano de publicação dos artigos, seis $(60 \%)$ correspondem ao ano de 2019 obtendo assim, uma maior representatividade. Os demais resultados encontram-se na tabela 1.

Tabela 1- Distribuição dos estudos incluídos na revisão, referente aos anos de publicação, compreendidos entre 2015 e 2019, Foz do Iguaçu, 2019.

\begin{tabular}{ccc}
\hline $\begin{array}{c}\text { Ano de } \\
\text { publicação }\end{array}$ & $\begin{array}{c}\text { Número } \\
\text { absoluto }\end{array}$ & $\%$ \\
\hline 2015 & 1 & 10 \\
2016 & 1 & 10 \\
2017 & & \\
2018 & 6 & 60 \\
2019 & 2 & 20 \\
2020 & $\mathbf{1 0}$ & 100 \\
\hline
\end{tabular}

Fonte: Bases de dados.

Em relação ao Quadro 1, tem-se a seguir uma sinopse que contém as principais características dos artigos selecionados neste trabalho, sendo os mesmos retratados com 
título do estudo, autor, ano de publicação, idioma e objetivo.

Quadro 1- Sinopse demonstrativa dos artigos compreendidos entre 2016 e 2020 incluídos no estudo.

\begin{tabular}{|c|c|c|c|c|}
\hline Título & $\begin{array}{c}\text { Base de } \\
\text { dados }\end{array}$ & Ano & Idioma & Objetivo \\
\hline $\begin{array}{l}\text { Epidemia da aids em } \\
\text { tríplice fronteira: subsídios } \\
\text { para a atuação profissional }\end{array}$ & SciELO & 2015 & Português & $\begin{array}{c}\text { Analisar temporalmente a tendência } \\
\text { da epidemia da Aids no município de } \\
\text { Foz do Iguaçu- PR, entre os anos de } \\
1988 \text { a } 2012 .\end{array}$ \\
\hline $\begin{array}{c}\text { Fatores determinantes da } \\
\text { dependência de crack na } \\
\text { tríplice fronteira - Brasil, } \\
\text { Bolívia e Paraguai }\end{array}$ & SciELO & 2017 & Português & $\begin{array}{l}\text { Caracterizar os fatores geradores da } \\
\text { dependência de crack/pasta-base no } \\
\text { MS utilizando como } \\
\text { instrumento ordenador a Matriz de } \\
\text { Corvalán. }\end{array}$ \\
\hline $\begin{array}{l}\text { Programa mais médicos em } \\
\text { município de fronteira } \\
\text { Internacional e os desafios } \\
\text { da gestão em saúde }\end{array}$ & SciELO & 2019 & Português & $\begin{array}{c}\text { Compreender as concepções de } \\
\text { gestores da APS } \\
\text { em região de fronteira trinacional } \\
\text { entre Brasil, Paraguai e Argentina } \\
\text { sobre a cooperação internacional em } \\
\text { saúde, baseando-se no processo de } \\
\text { implantação do PMM. }\end{array}$ \\
\hline $\begin{array}{l}\text { A assistência à saúde } \\
\text { transfronteira e o } \\
\text { prognóstico da infecção } \\
\text { pelo HIV na tríplice } \\
\text { fronteira Brasil-Paraguai- } \\
\text { Argentina }\end{array}$ & Lilacs & 2019 & Inglês & $\begin{array}{l}\text { Comparar o prognóstico de pacientes } \\
\text { com HIV que residem na mesma } \\
\text { cidade do estabelecimento de saúde } \\
\text { (Foz do Iguaçu) com pacientes } \\
\text { oriundos de cidades vizinhas menores } \\
\text { do Brasil (mobilidade regional) e } \\
\text { pacientes que cruzam o internacional. } \\
\text { fronteira com o Paraguai para buscar } \\
\text { atendimento médico (atendimento } \\
\text { transfronteiriço) no Serviço de } \\
\text { Assistência Especializada (SAE) de } \\
\text { Foz do Iguaçu. }\end{array}$ \\
\hline $\begin{array}{l}\text { Consumo de álcool e drogas } \\
\text { e participação em violência } \\
\text { por adolescentes de uma } \\
\text { região trinacional }\end{array}$ & Lilacs & 2019 & Português & $\begin{array}{c}\text { Identificar a associação entre o } \\
\text { consumo de drogas e álcool e a } \\
\text { participação em violência de } \\
\text { adolescentes da tríplice fronteira, de } \\
\text { três municípios/países: Brasil, } \\
\text { Paraguai e Argentina. }\end{array}$ \\
\hline $\begin{array}{l}\text { Acesso à atenção primária } \\
\text { na Tríplice Fronteira sob a } \\
\text { ótica do brasileiro não } \\
\text { residente no país }\end{array}$ & CAPES & 2019 & Português & $\begin{array}{l}\text { Descrever como ocorre o acesso na } \\
\text { atenção primária à saúde de brasileiros } \\
\text { não residentes no país. }\end{array}$ \\
\hline $\begin{array}{l}\text { Possibilidades e limitações } \\
\text { da terapia nutricional } \\
\text { enteral na compreensão de } \\
\text { cuidadores e profissionais } \\
\text { de uma rede pública de } \\
\text { saúde em região de } \\
\text { fronteira }\end{array}$ & CAPES & 2019 & Português & $\begin{array}{l}\text { Analisar possibilidades, limites e } \\
\text { desafios da terapia de nutrição enteral } \\
\text { domiciliar na rede pública de saúde e } \\
\text { o perfil nutricional de pacientes pós- } \\
\text { alta hospitalar de Foz do Iguaçu, PR }\end{array}$ \\
\hline $\begin{array}{l}\text { Migração haitiana e direitos } \\
\text { humanos: o acesso à saúde } \\
\text { pública em região de } \\
\text { fronteira no Brasil }\end{array}$ & CAPES & 2019 & Português & $\begin{array}{l}\text { Problematizar o tema da desigualdade } \\
\text { social expressa cotidianamente como } \\
\text { uma desigualdade em saúde. }\end{array}$ \\
\hline
\end{tabular}


Revisão de Literatura

\begin{tabular}{|c|c|c|c|c|}
\hline $\begin{array}{c}\text { Intervenções intersectoriais } \\
\text { em indicadores de saúde de } \\
\text { Adolescentes }\end{array}$ & SciELO & 2020 & Português & $\begin{array}{c}\text { Apresentar a avaliação de uma } \\
\text { intervenção intersectorial em } \\
\text { indicadores de saúde de adolescentes } \\
\text { de uma região de fronteira. }\end{array}$ \\
\hline $\begin{array}{c}\text { O acesso à saúde em região } \\
\text { fronteira: a tríplice fronteira } \\
\text { Argentina, Brasil e Paraguai } \\
\text { em meio à pandemia do } \\
\text { coronavírus }\end{array}$ & SciELO & 2020 & Português & $\begin{array}{c}\text { Analisar as políticas públicas de } \\
\text { acesso à saúde ao migrante e suas } \\
\text { implicações em tempos de Covid-19 }\end{array}$ \\
\hline
\end{tabular}

Fonte: Bases de dados utilizadas no estudo (2020).

Sabe-se que o alcance a serviços de saúde geograficamente restritos pela fronteira entre três países faz com que a procura por cuidados de brasileiros moradores no Paraguai ou na Argentina seja um desafio. Dessa forma, Lima e $\mathrm{Toso}^{2}$ realizaram um estudo para descrever como ocorre o acesso na atenção primária à saúde de brasileiros não residentes no país. Para a elaboração da pesquisa foram entrevistados treze usuários da atenção primária do município de Foz do Iguaçu. ${ }^{2}$ Segundo os entrevistados, na atenção primária referida pelos usuários não residentes, careceram de estratégias para a acessibilidade e coordenação do cuidado, todavia a conseguiram o acesso. ${ }^{2}$

De acordo com os autore ${ }^{2}$ a unidade de saúde opera o modelo tradicional, o que não dificulta a adoção de novos artifícios de trabalho. Ademais, a organização local das ofertas de atenção necessita ponderar a dimensão da população a ser auxiliada, nesse caso, abrangendo os brasileiros não residentes. Incluídas, essas intervenções poderiam resultar em ampliação na resolutividade do cuidado a esses brasileiros. $^{2}$

Um novo estudo ${ }^{13}$ teve como intuito problematizar o tema da desigualdade social expressa cotidianamente na tríplice fronteira como uma desigualdade em saúde os autores encontraram uma variável importante. Observaram na pesquisa o descontentamento generalizado dos pacientes com o acolhimento médico recebido nas unidades. ${ }^{13}$ De acordo com os autores, mesmo quem nunca passou por algum tipo de insulto, avalia o atendimento como insatisfatório. Isso expõe condições problemáticas de trabalho, carência de recursos materiais e no número de trabalhadores. Os autores afirmam ainda que apesar desse problema estrutural não estar presente no enquadramento do estudo, cabe enfatiza-lo como uma particularidade nodal do campo analisado. ${ }^{13}$

Nesse contexto Feitosa, Martins e Jaqueira ${ }^{11}$ afirmam que tal gargalo se dá pelas desigualdades estruturais de entrada nos sistemas de saúde de cada país, o que corrobora com as problemáticas de acesso a tecnologias indispensáveis para a sustentação diagnóstica das condições de saúde ou mesmo para definição de terapêuticas. $\mathrm{O}$ mesmo pensamento vai ao encontro com o estudo de Zaslavsky Goulart e Ziegelmann ${ }^{14: 5}$ que afirmam que:

"[...] Nos países em desenvolvimento, esse tipo de mobilidade de pacientes para atendimento à saúde é comum em áreas de fronteira, com o fluxo de pessoas na direção da cidade com mais recursos de saúde, principalmente quando as disparidades sociais e econômicas entre os países são grandes e o consequente acesso e qualidade dos cuidados de saúde. Apesar do exposto, nesses países o número de pacientes que cruzam a fronteira em busca de assistência médica é mal monitorado ${ }^{18,19}$ e seu impacto nos desfechos de saúde ainda é desconhecido. A migração pendular para atendimento à saúde é o tipo mais comum de atendimento transfronteiriço na tríplice fronteira Brasil-ParaguaiArgentina".

Os autores supracitados ${ }^{14}$, realizaram um estudo para comparar o prognóstico de pacientes com HIV que residem na mesma cidade do estabelecimento de saúde (Foz do Iguaçu) com pacientes oriundos de cidades vizinhas menores do Brasil (mobilidade regional) e pacientes que cruzam a fronteira internacional com o Paraguai para buscar atendimento médico (atendimento transfronteiriço) no Serviço de Assistência Especializada (SAE), de Foz do Iguaçu. Neste estudo de coorte retrospectivo, "a exposição à 
migração regional e internacional não teve uma associação significativa com o risco de morte por qualquer causa em análises brutas ou ajustadas para fatores prognósticos já conhecidos". 14:188 Apesar dessas descobertas, os autores destacam, a obrigação de monitorar a extensão e as particularidades clínicas e demográficas da demanda de saúde existente do outro lado da fronteira e o emprego dessas informações para a tomada de decisão na gestão da saúde. ${ }^{14}$

$\mathrm{Na}$ mesma linha de pesquisa, um estudo $^{15}$ analisou temporalmente a tendência da epidemia da Aids no município de Foz do Iguaçu- PR, entre os anos de 1988 a 2012. Os resultados do estudo mostraram que a epidemia da Aids no município de Foz do Iguaçu expôs modificações no transcorrer dos anos de 1988 a 2012, o que levou a conversão de um novo panorama epidemiológico, com um aspecto caracterizado especialmente pela feminização e heterossexualização da doença, além do avanço de notificações entre sujeitos com mais anos de estudo. ${ }^{15}$

Acredita-se que com a compreensão das características deste contexto, distinto de outros lugares, por ser uma região de tríplice fronteira, torna-se possível refletir a efetivação de políticas públicas que garantam o acesso equitativo de homens e mulheres a prevenção, atenção e acolhimento em todos os domínios públicos. $^{15}$

Nesse cenário, um estudo ${ }^{16}$ buscou compreender as concepções de gestores da APS em região de fronteira trinacional entre Brasil, Paraguai e Argentina sobre a cooperação internacional em saúde, baseandose no processo de implantação do Projeto Mais Médicos (PMM). Na percepção dos gestores, o Projeto colaborou para a sustentação da oferta de serviços na Atenção Primária local, e é uma abertura para a garantia de prestação do amparo médico em município de região fronteiriça. ${ }^{16}$

Os autores ressaltam ainda que a colaboração técnica em saúde em região fronteiriça na América Latina pode ser uma significativa tática para consolidar os debates sobre o trabalho na APS e suas debilidades ainda permanentes após 40 anos de AlmaAta. ${ }^{16}$ Os pesquisadores acreditam que os subsídios da pesquisa podem fortalecer os mecanismos locais da APS em região de fronteira, sobretudo no encaminhamento da cooperação em saúde como tecnologia para qualificação da saúde pública. ${ }^{16}$

Durante a presente pesquisa também foram encontrados trabalhos relacionados ao uso de álcool e drogas ${ }^{17-19}$ na tríplice fronteira, entre eles, está o estudo de Priotto e Silva ${ }^{17}$, que teve como objetivo identificar a associação entre o consumo de drogas e álcool e a participação em violência de adolescentes da tríplice fronteira, de três municípios/países: Brasil, Paraguai e Argentina. De acordo com os dados apresentados, os autores reforçam que a região de fronteira entre o Brasil e o Paraguai se compõe em uma importante região do caminho de tráfico de drogas, movimento este que potencializa o uso/consumo de drogas e a criminalidade; uma complicada rede ilegal nesta região. ${ }^{17}$

No entanto, ao contrário do esperado, evidenciou-se que apesar dos adolescentes habitarem em municípios de fronteira, com alto índice de apreensão de drogas, tráfico e criminalidade, estes expuseram uma percentual menor na ingestão de drogas ilícitas e uma associação estatisticamente expressiva para o consumo de álcool e o tabaco, drogas lícitas, de baixo custo e alcance facilitado, o que beneficia a aceitação social, sendo esses, adolescentes, participantes da violência na tríplice fronteira. ${ }^{17}$

Nesse sentido, discorrendo no panorama de fronteiras fechadas, Covid-19 e migração, informações da Organização Internacional de Migrações (OIM) apontam que em torno de $57 \%$ dos migrantes desistiram ou tardaram seu planejamento migratório em função da pandemia. Além disso, em torno de $21 \%$ dos migrantes tem a aspiração ou intuito de regressar aos seus países de ascendência e destes $50 \%$ almejam retornar por não possuir remuneração e o elevado custo de vida no país de destino e $18 \%$ anseiam voltar devido ao desemprego. ${ }^{11}$

Neste cenário, outros dados significativos que impossibilitam o retorno dos migrantes ao seu país de origem, 34\% responderam que não podem regressar por causa das restrições de mobilidade e outros $56 \%$ não possuem dinheiro suficiente para realizar o seu retorno. Assim sendo, perante a 
apreciação destas informações contata-se que os migrantes que estão impedidos de regressar ou prosseguir seu plano migratório se encontram em uma circunstância de vulnerabilidade econômica e social. ${ }^{11}$

Se na conjuntura antecedente à crise sanitária, os migrantes já se deparavam com dificuldades de acesso à saúde, conforme já exposto no presente trabalho se faz imprescindível repensar as políticas de públicas e de governança migratória para a saúde, conforme expõe Alpuche-Aranda:

"[...] Es una obligación de todos los países trabajar de manera integrada en planes de preparación y respuesta ante eventos críticos de salud pública, como es el caso de enfermedades infecciosas emergentes, para lograr tener un país y un mundo seguros y saludables. Ante estos eventos, una de las lecciones más importantes es compartir lo que hemos aprendido y mantener la honesta transparencia y responsabilidad en la información y en las acciones de respuesta". 18:124

Desta forma, observa-se como indispensável e urgente refletir em políticas de saúde por meio de ações intergovernamentais e uma participação mais intensificada dos Ministérios de Saúde dos países fronteiriços para debater e implementar medidas de migração e saúde, pois a falta de articulação de política migratória e de saúde sujeita esta população a uma precarização de suas vidas, a precarização da condição humana em um cenário de pandemia e a necessidade imediata do acesso a saúde..$^{20-21}$

\section{CONCLUSÃO}

Sabe-se que as diferentes fronteiras brasileiras conectam países com distintas peculiaridades naturais e humanas, o que faz desses espaços, lugares com particularidades, como é o caso da tríplice fronteira ArgentinaBrasil-Paraguai, que se sobressai pela ampla movimentação de pessoas, contrastado às outras fronteiras.

Como evidenciado nas pesquisas sobre as cidades fronteiriças, a desigualdade nos sistemas de saúde dos países vizinhos influencia na procura por atendimento, e no panorama da crise ocasionada pela pandemia do novo coronavírus, que acarretou o fechamento de inúmeras fronteiras, algumas de maneira parcial e outras totalmente, como as da tríplice fronteira em estudo, esses indivíduos se encontram em maior estado de vulnerabilidade, principalmente aqueles que não possuem um lugar para se abrigar, ou até mesmo documentação, que é o mínimo requerido para ter atendimento.

Por fim, em limites de fronteira de países com grandes desigualdades socioeconômicas, é imprescindível debater e implementar políticas locais para diminuir a carência de acesso e a discrepância na qualidade da saúde. Acredito que este estudo, em vez de encerrar teses de investigação e assinalar para uma resposta mais determinante, coopera para abrir o campo de verificação sobre o impacto na saúde dos cuidados transfronteiriços para pacientes e serviços.

\section{REFERÊNCIAS}

1. Giovanella L, Guimarães L, Nogueira VMR, Lobato LDVC, Damacena GN. Saúde nas fronteiras: acesso e demandas de estrangeiros e brasileiros não residentes ao SUS nas cidades de fronteira com países do MERCOSUL na perspectiva dos secretários municipais de saúde. Cadernos de Saúde Pública. 2007; 23: 251-266.

2. Lima LTP, Toso BRG. O Acesso a atenção primária na tríplice fronteira sob a ótica do brasileiro não residente no país. Revista de Saúde Pública do Paraná. 2019;2(1):13-20.

3. Giovanella L, Almeida PF. Atenção primária integral e sistemas segmentados de saúde na América do Sul. Cad. Saúde Pública: 2017;33(2).

4. Brasil. Constituição da República Federativa do Brasil. Brasília: Senado Federal; 1988. [Acesso em 2021 Fev 01] Disponível em: http://www.senado.gov.br/ legislacao/const/.

5. Cazola LHDO, Pícoli RP, Tamaki EM, Pontes ER, Ajalla ME. Atendimentos a 
brasileiros residentes na fronteira BrasilParaguai pelo Sistema Único de Saúde. Revista Panamericana de Salud Pública. 2011; 29:185190.

6. Gadelha CAG, Costa L. Integração de fronteiras: a saúde no contexto de uma política nacional de desenvolvimento. Cad Saude Publica. 2007; 23 (2): 214-26.

7. Frasson M, Schlosser MTS. Fronteiras na fronteira: a trajetória dos migrantes brasiguaios e a influência econômico-jurídico-políticoideológica dos Estados nacionais (BR e PY), a origem do aluno brasiguaio. Caderno de Geografia. 2015; 25(44);]70-96.

8. Foz do Iguaçu, secretaria municipal da saúde. Relatório Anual de Gestão 2015. [Acesso em 2021 Fev 01] Disponível em: http://www.

pmfi.pr.gov.br/ArquivosDB?idMidia=97328.

9. Peron VD, Lisboa MT. Cooperação Internacional e Política Públicas: a atuação do GT-Saúde na Tríplice Fronteira. 2017.

10. Peiter PC. A geografia da saúde na faixa de fronteira continental do Brasil na passagem do milênio. Rio de Janeiro: Instituto de Geociências, Universidade Federal do Rio de Janeiro; 2005.

11. Feitosa TVN, Martins W, Jaqueira M. O acesso à saúde em região fronteira: a tríplice fronteira Argentina, Brasil e Paraguai em meio à pandemia do coronavírus. Boletim de Conjuntura (BOCA). 2020;4(11);28-41.

12. Souza MTD, Silva MDD, Carvalho RD. Integrative review: what is it? How to do it? Einstein (São Paulo). 2010:8(1);102-106.

13. Silva AF, Lalane JB. Migração haitiana e direitos humanos: o acesso à saúde pública em região de fronteira no Brasil. Research, Society and Development. 2019:8(9);17.
14. Zaslavsky R, Goulart B, NGD, Ziegelmann PK. Cross-border healthcare and prognosis of HIV infection in the triple border BrazilParaguay-Argentina. Cadernos de saúde pública. 2019;35:184-918.

15. Mombelli MA, Barreto MDS, Arruda GOD, Marcon SS. Epidemia da Aids em tríplice fronteira: subsídios para a atuação profissional. Revista Brasileira de Enfermagem. 2015;68(3):429-437.

16. Arenhart, CGM, Gomes, LMX, Ribeiro, EM, Barbosa, TLDA. Programa mais médicos em município de fronteira internacional e os desafios da gestão em saúde. Trabalho, Educação e Saúde. 2019;17(3).

17. Priotto EMTP, Silva MAI. Consumo de álcool e drogas e participação em violência por adolescentes de uma região trinacional. SMAD Revista Eletrônica Saúde Mental Álcool e Drogas. 2019;15 (3):1-9.

18. Alpuche-Aranda CM. "Infecciones emergentes, el gran reto de la salud global: Covid-19”. Salud Pública de México. 2020;62 (2).

19. Veras AB. Fatores determinantes da dependência de Crack na tríplice fronteiraBrasil, Bolívia e Paraguai. Interações (Campo Grande). 2016;17(1):126-133.

20. Corrêa R, Almeida S, Almeida A, Matos MGD, Barros P. Intervenções intersectoriais em indicadores de saúde de adolescentes. Psicologia, Saúde \& Doenças, 2020;21(1):2937.

21. Führ AL. Possibilidades e limitações da terapia nutricional enteral na compreensão de cuidadores e profissionais de uma rede pública de saúde em região de fronteira. Revista Demetra. 2019;14.

Recebido em: 01.02.2021

Aprovado em: 26.07.2021 